\title{
AN EMPIRICAL TeST OF the Hull-White Option Pricing Model
}

\section{ChaRles CorRado TIE SU*}

\section{INTRODUCTION}

The Black-Scholes (1973) option pricing model provides the foundation for the modern theory of options valuation. In actual applications, however, the model has certain well-known deficiencies. For example, when calibrated to accurately price at-the-money options the Black-Scholes (1973) model often misprices deep in-the-money and deep out-of-themoney options. This model-anomalous behavior gives rise to what options professionals call "volatility smiles." A volatility smile is the skewed pattern that results from calculating implied volatilities across a range of strike prices for an option series. This phenomenon is not predicted by the Black-Scholes (1973) model, since volatility is a property of the underlying instrument and the same implied volatility value should be observed across all options on that instrument. Volatility smiles are generally thought to result from the parsimonious assumptions used to derive the Black-Scholes model. In particular, the Black-Scholes (1973) model assumes that security log prices follow a constant variance diffusion process. The constant variance assumption has been tested and rejected in early studies by Beckers (1980), Black and Scholes (1972), Christie

${ }^{*}$ Correspondence author, Department of Finance, University of Miami, P.O. Box 248094, Coral Gables, FL 33124-6552.

- Charles Corrado is an Associate Professor of Finance at the University of MissouriColumbia.

- Tie Su is an Assistant Professor in the Department of Finance at the University of Miami. 
(1982), Officer (1973), and Schmalensee and Trippi (1978). Since then a considerable body of research, most notably the conditional heteroskedasticity literature originating with Engle (1982) and Bollerslev (1986), has documented the stochastic character of security return variances. Bollerslev, Chou, and Kroner (1992) have surveyed this large body of literature. To summarize, financial econometricians have produced overwhelming evidence that security return variances are stochastic and typically correlated with security prices. Under these conditions, Heston (1993), Hull and White (1987), Scott (1987), Stein and Stein (1991), Wiggins (1987), Hillard and Schwartz (1996), and others show that the Black-Scholes (1973) model predicts option prices expected to systematically deviate from observed option prices.

This article studies the stochastic volatility process for the Standard and Poor's 500 index implied by S\&P 500 index (SPX) option prices. The major tool for this analysis is the stochastic volatility option pricing formula derived by Hull and White (1988). The Hull and White (1988) formula is an appealing choice, most importantly because it is sufficiently flexible to allow a wide range of stochastic volatility specifications, including an arbitrary correlation between security return volatility and security price changes. In addition, the Hull and White (1988) formula readily lends itself to the estimation of underlying stochastic process parameters. This article contributes to the stochastic volatility literature by reporting direct estimates of the parameters of a true stochastic volatility process (i.e., where volatility is not a deterministic function of the underlying cash price) obtained as implied parameters from observed option prices. The procedures followed here represent a substantial generalization of the widespread practice of obtaining an implied standard deviation from observed option prices.

\section{STOCHASTIC VOLATILITY OPTION PRICING MODELS}

Stock return volatility processes are an important topic in option pricing theory. Consequently, they have received considerable attention in the literature. This literature originates with Merton (1976a, 1976b) and Cox and Ross (1976), who developed the first option pricing models allowing a nonconstant return variance. Merton (1976a) assumes a mixture of continuous and jump processes, while Cox and Ross (1976) allow return volatility to be a deterministic function of the underlying stock price. Later, Scott (1987) assumes that return volatility follows a continuous diffusion process and Johnson and Shanno (1987) propose a stochastic volatility model where stock returns and return volatility are correlated. 
Wiggins (1987) derives statistical estimators for volatility process parameters and calculates parameter estimates for several individual stocks and stock indexes. Using Monte Carlo estimation methods, he finds that where correlations between volatility movements and stock returns are positive, out-of-the-money call options increase in value relative to BlackScholes prices, while in-the-money call options decrease in value. This effect is reversed where correlations are negative.

Hull and White (1987) analyze European call options on a stock price subject to stochastic volatility. Using a Taylor series expansion, they derive an accurate formula for call options where stock returns and stock volatilities are uncorrelated. In a related article, Hull and White (1988) relax the zero correlation restriction. Dothan (1987) also derives an accurate formula for biases in the Black-Scholes (1973) model induced by stochastic volatility with nonzero correlation between stock returns and return variances. Stein and Stein (1991) derive a stochastic volatility option pricing formula that assumes return volatility follows an OrnsteinUhlenbeck (AR1) process and Heston (1993) develops a closed form solution for options with stochastic volatility.

In summary, prior research has led to the development of a variety of stochastic volatility option pricing models. Unfortunately, empirical applications of these models have been limited. Major exceptions are Bates (1996), who estimates the parameters of a joint stochastic volatilityjump diffusion model as implied by deutsche mark options, and Bakshi, Cao, and Chen (1997), who estimate a similar parameter set for the S\&P 500 index. This study applies the stochastic volatility model specified by Hull and White (1988) to examine the stochastic process for the S\&P 500 index. This choice is motivated by the model's flexibility and adaptability to parameter estimation. This study is based on options on the S\&P 500 index traded on the Chicago Board Options Exchange (CBOE). Repeated perusals through The Wall Street Journal reveal that these options (the SPX contracts) are the most heavily traded European style index options in the world.

\section{METHODOLOGY}

Hull and White (1988) assume the following stochastic processes for a security price and its return volatility:

$$
\begin{aligned}
& d S / S=\phi d t+\sqrt{V} d z \\
& d V=\eta d t+\xi \sqrt{V} d w
\end{aligned}
$$


Following the notation in Hull and White (1988), $S$ is a stock price, $V$ is an instantaneous stock return variance, and $d z, d w$ are Wiener processes with correlation, $\rho . \xi$ is the instantaneous standard deviation of $d V / \sqrt{V}$. $\phi$ is the exponential drift rate of $S$ and $\eta(V)=a+b V$ is the instantaneous drift rate of $V$, where $a$ and $b$ are constants. Mean-reverting volatility assumes that $b$ is negative with a long-run reversion value of $-a / b$, where $a$ must be positive to maintain a positive variance. The Hull-White (1988) option pricing model assumes that the parameters, $\rho, \xi$, $a$, and $b$, are constant. Time varying parameters could be used in this model. However, cointegration concerns and correlations among time, varying parameters may yield unstable estimates and considerably complicate the estimation routine. Instead, constant parameters over short intervals are chosen.

While Heston (1993) provides a closed form solution for an option price on an asset price following the stochastic volatility process specified in eq. (1), the solution requires evaluation of a difficult integral expression. Fortunately, Hull and White (1988) provide an accurate approximation from a second-order Taylor series expansion around a constant volatility specification $(\xi=0)$. Using this expansion, they show that the stochastic volatility bias of the Black-Scholes (1973) model is accurately measured by the following expression:

$$
\text { Bias }=Q_{1} \rho \xi+\left(Q_{2}+Q_{3} \rho^{2}\right) \xi^{2}+o\left(\xi^{2}\right)
$$

Assuming that volatility is initially at its long-run reversion value, i.e., $V$ $=-a / b$, the coefficients $Q_{j}$ in eq. (2) are defined as follows, where $\delta=$ $b \tau$.

$$
\begin{aligned}
Q_{1} & =-\frac{1}{b^{2} \tau} V\left(1+\delta-e^{\delta}\right) S \frac{\partial^{2} C}{\partial S \partial V} \\
Q_{2} & =\frac{1}{4 b^{3} \tau^{2}} V\left(e^{2 \delta}-4 e^{\delta}+2 \delta+3\right) \frac{\partial^{2} C}{\partial V^{2}} \\
Q_{3} & =-\frac{1}{b^{3} \tau} V\left(e^{\delta}(2-\delta)-(2+\delta)\right) S \frac{\partial^{2} C}{\partial S \partial V}+\frac{2}{b^{3} \tau^{2}} V\left(e^{\delta}(2-\delta)-(2+\delta)\right) \frac{\partial^{2} C}{\partial V^{2}} \\
& +\frac{1}{2 b^{4} \tau^{2}} V^{2}\left(1+\delta-e^{\delta}\right)^{2} S \frac{\partial^{3} C}{\partial S \partial V^{2}}+\frac{1}{b^{4} \tau^{3}} V^{2}\left(1+\delta-e^{\delta}\right)^{2} \frac{\partial^{3} C}{\partial V^{3}}
\end{aligned}
$$

Adding this bias to the Black-Scholes call price yields the Hull and White stochastic-volatility-adjusted call price, here denoted by $C_{H W}$ :

$$
C_{H W}=C_{B S}(V)+Q_{1} \rho \xi+Q_{2} \xi^{2}+Q_{3} \rho^{2} \xi^{2}
$$


For reference, the Black-Scholes call price with strike price, $K$, time to option expiration, $\tau$, and interest rate, $r$, is stated as

$$
\begin{aligned}
C_{B S} & =S N\left(d_{1}\right)-K e^{-r \tau} N\left(d_{2}\right) \\
d_{1} & =\frac{\log (S / K)+(r+V / 2) \tau}{\sqrt{V \tau}} \quad d_{2}+d_{1}-\sqrt{V \tau}
\end{aligned}
$$

Equation (4) is the fundamental equation of this study. Assuming a constant variance, i.e., $\xi=0$, the pricing bias is zero and eq. (4) collapses to the Black-Scholes call price formula. If $\xi>0$, then eq. (4) is the sum of a Black-Scholes call price and adjustments for the stochastic volatility process specified in eq. (1b). This study applies eq. (4) to estimate the parameters of this stochastic volatility process from observed options price data.

\section{DATA SOURCES}

Options price data for this study come from the Berkeley Options Database of options traded on the CBOE. Option contracts for the S\&P 500 index (the SPX contracts) are used. Option prices, stock index levels, strike prices, and option expirations come directly from the Berkeley Options Database. To avoid bid-ask bounce problems in transactions data, option prices are taken as midpoints of bid-ask price quotes. Interest rates used are yields on Treasury bills with maturities closest to option expirations. Interest rate data are culled from The Wall Street Journal.

Since S\&P 500 index options are European style, the method suggested by Black (1975) is used to adjust cash index levels by subtracting present values of future dividend payments occurring before each option's expiration date. Daily dividends for the S\&P 500 index are obtained from the SEP 500 Information Bulletin.

Following data screening procedures in Barone-Adesi and Whaley (1986), all options with prices less than $\$ 0.125$ and option transactions occurring before 9:00 AM are deleted. Obvious outliers are purged also from the sample, including option prices that lie outside well-known noarbitrage option price boundaries (Merton, 1973). An estimation procedure is performed on all data available from the Berkeley Options Database. The results are similar across different periods. Results obtained from option price quotations for contracts traded in February and April 1995 are reported because they are the most recent data in the sample. 


\section{ESTIMATION PROCEDURES AND RESULTS}

The first set of estimation procedures assesses the out-of-sample performance of the Black-Scholes option pricing formula. Specifically, implied standard deviations (ISD) are estimated on a daily basis for call options on the S\&P 500 index where, on the day prior to a given current day, a unique ISD is obtained from all bid-ask price midpoints using Whaley's (1982) simultaneous equations procedure. This prior-day ISD is then used as an input to calculate theoretical Black-Scholes option prices for all current-day price observations. The theoretical Black-Scholes prices based on an out-of-sample ISD are compared to their corresponding market-observed prices.

The second set of estimation procedures assesses the out-of-sample performance of the Hull and White stochastic volatility option pricing formula. Ipso facto, this second step includes out-of-sample parameter estimates for the stochastic volatility process specified in Hull and White (1988). These out-of-sample parameter values are then used to calculate theoretical option prices for all option price observations. These theoretical option prices are compared to their corresponding market-observed prices.

\section{BLACK-SCHOLES OPTION PRICING MODEL}

The Black-Scholes formula requires five inputs: a security price, a strike price, a risk-free interest rate, an option maturity, and a return standard deviation. The first four inputs are directly observable from market data. Only the return standard deviation is not directly observable. Out-ofsample return standard deviations are estimated from values implied by options based on the simultaneous equations procedure suggested by Whaley (1982). A simultaneous equations estimate is the value of the argument, BSISD, which minimizes the following sum of squares:

$$
\min _{B S I S D} \sum_{j=1}^{N}\left[C_{O B S}-C_{B S}(B S I S D)\right]^{2}
$$

In eq. (6), $N$ is the number of bid-ask price quotes sampled on a given prior day, $C_{O B S}$ is a market-observed call price, and $C_{B S}(B S I S D)$ is a theoretical Black-Scholes call price calculated using the standard deviation parameter, BSISD. Based on the value of BSISD that minimizes the sum of squared errors in eq. (6), theoretical Black-Scholes option prices are calculated for all options in a given current day's sample. These theo- 
TABLE I

Comparison of Black-Scholes Prices and Observed Prices of S\&P 500 Index Options (SPX)

\begin{tabular}{|c|c|c|c|c|c|c|}
\hline $\begin{array}{l}\text { Trading } \\
\text { Date }\end{array}$ & $\begin{array}{c}\text { Number of } \\
\text { Price } \\
\text { Observations }\end{array}$ & $\begin{array}{r}\text { ISD } \\
(\%)\end{array}$ & $\begin{array}{c}\text { Proportion of } \\
\text { Theoretical Prices } \\
\text { Outside Bid-Ask } \\
\text { Spreads }\end{array}$ & $\begin{array}{c}\text { Average Deviation } \\
\text { of Theoretical Price } \\
\text { from Spread } \\
\text { Boundaries }(\$)\end{array}$ & $\begin{array}{c}\text { Average } \\
\text { Call Price (\$) }\end{array}$ & $\begin{array}{c}\text { Average } \\
\text { Bid-Ask Spread } \\
\text { (\$) }\end{array}$ \\
\hline 2/2/95 & 213 & 11.75 & 0.93 & 1.30 & 17.28 & 0.59 \\
\hline 2/6/95 & 239 & 11.23 & 0.96 & 1.30 & 20.57 & 0.57 \\
\hline 2/8/95 & 241 & 11.43 & 0.96 & 1.33 & 21.42 & 0.58 \\
\hline 2/10/95 & 242 & 11.31 & 0.95 & 1.13 & 21.22 & 0.61 \\
\hline 2/14/95 & 203 & 11.27 & 0.96 & 1.08 & 20.59 & 0.58 \\
\hline 2/16/95 & 203 & 11.85 & 0.94 & 1.42 & 21.89 & 0.55 \\
\hline 2/22/95 & 222 & 11.75 & 0.91 & 1.48 & 20.71 & 0.64 \\
\hline 2/24/95 & 227 & 11.87 & 0.95 & 1.35 & 22.61 & 0.64 \\
\hline 2/28/95 & 212 & 11.92 & 0.96 & 1.13 & 15.53 & 0.55 \\
\hline Average & 222 & 11.60 & 0.95 & 1.28 & 20.20 & 0.59 \\
\hline
\end{tabular}

Notes: On each day indicated, an ISD is estimated from one-day lagged price observations. Theoretical Black-Scholes option prices are then calculated using this ISD. All price observations correspond to call options traded in February 1995.

retical Black-Scholes option prices are then compared to their corresponding market-observed prices.

An efficient options market is assumed, in which dealers set bid-ask prices to bracket what they accurately perceive to be a correct but unobserved price. In this setting, an option pricing model can do no better than predict a price that lies within an observed bid-ask spread. Therefore, the pricing error is measured as the difference between a modelpredicted price and a bid-ask spread boundary, and it is assignedrror if the model-predicted price lies within a bid-ask spread. The logic behind this measure is that in an efficient options market, one can only invalidate an option pricing model when it systematically yields predicted prices outside observed bid-ask spreads. By contrast, prior studies typically measure pricing error by the difference between a model-predicted price and a bid-ask price average. This method yields larger measured pricing errors, and therefore may overstate an assessment of noise in the trading process.

Table I summarizes the calculations for S\&P 500 index call option prices observed during February 1995. Column 1 lists sampling dates within the month. To maintain table compactness, results are reported for only even-numbered dates within the month. Column 2 lists the number of price quotes available on each date. One-day lagged Black-Scholes implied standard deviations (BSISD) for each date are reported in column 3. To assess the out-of-sample economic significance of differences be- 
tween theoretical and observed prices, column 4 lists the proportion of theoretical Black-Scholes option prices lying outside their corresponding observed bid-ask spreads, either below a bid price or above an asked price. Column 5 lists average absolute deviations of theoretical prices from bid-ask boundaries for only those theoretical prices lying outside their bid-ask spreads. Specifically, for each theoretical option price lying outside its corresponding bid-ask spread, an absolute deviation is calculated using the following formula:

$$
\max \left(C_{B S}(B S I S D)-A s k, B i d-C_{B S}(B S I S D)\right)
$$

This absolute deviation statistic measures the economic significance of deviations of theoretical option prices from observed bid-ask spreads. Finally, column 6 lists day-by-day averages of observed call prices and column 7 lists day-by-day averages of observed bid-ask spreads.

In Table I, column averages for all variables are listed in the bottom row. For example, the average number of daily price observations sampled is 222 (column 2), with an average option price of $\$ 20.20$ (column 6) and an average bid-ask spread of $\$ 0.59$ (column 7). The average ISD is $11.60 \%$ (column 3). Regarding the ability of the Black-Scholes model to predict option prices, the average proportion of theoretical Black-Scholes prices lying outside their corresponding bid-ask spreads is 95\% (column 4 ), with an average deviation of $\$ 1.28$ for those observations lying outside a spread boundary. This average deviation is more than twice as large as the average bid-ask spread of $\$ 0.59$.

A visual representation of deviations of observed call prices from theoretical Black-Scholes call prices is displayed by the black squares in Figure 1 for the 212 price quotes observed on 28 February 1995. Option moneyness is measured on the horizontal axis and price deviations are measured on the vertical axis. Option moneyness is a percentage calculated as follows, where $S_{0}$ is a dividend-adjusted cash price and $K e^{-r t}$ is a discounted strike price:

$$
\text { Moneyness }(\%)=100 \times \frac{K e^{-r \mathrm{t}}-S_{0}}{K e^{-r \mathrm{t}}}
$$

Negative (positive) moneyness corresponds to in-the-money (out-of-themoney) call options with low (high) strike prices. Price deviations measured on the vertical axis are observed prices minus theoretical prices. So defined, the zero horizontal axis corresponds to theoretical Black-Scholes prices and the dots correspond to observed call prices relative to theoretical Black-Scholes prices. 


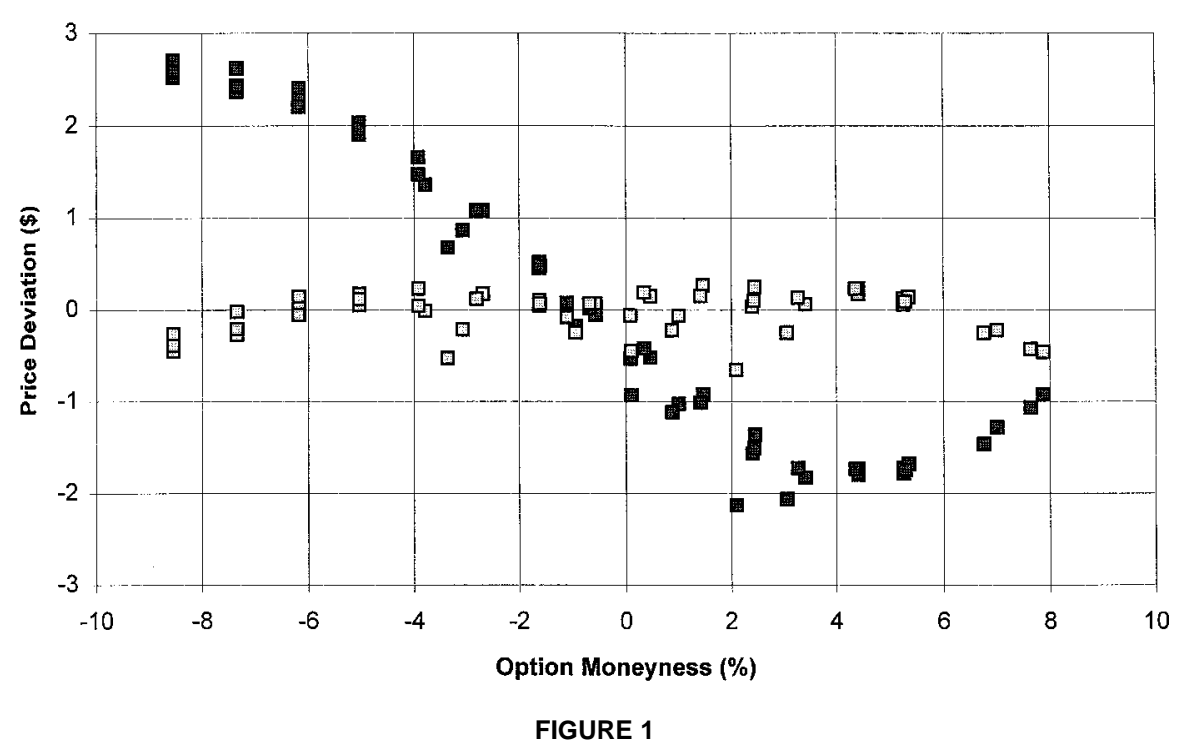

Mispricing of the Black-Scholes model and the Hull-White model (February 1995).

Figure 1 graphically reveals that the Black-Scholes formula overvalues out-of-the-money options and undervalues in-the-money options for this sample of S\&P 500 index call options. Moreover, Figure 1 shows that observed option prices corresponding to deep in-the-money or out-of-themoney options often deviate from theoretical prices by several dollars.

\section{STOCHASTIC VOLATILITY OPTION PRICING MODEL}

In the second set of estimation procedures, on the day prior to a given current day, stochastic volatility parameters are estimated for the stochastic volatility model specified by Hull and White (1988). The stochastic volatility process assumed by Hull and White (1988) has four parameters that must be estimated. These are an instantaneous return variance $(V)$, a volatility of volatility $(\xi)$, a correlation between stock returns and variance changes $(\rho)$, and a coefficient of mean reversion $(b)$. These parameters are estimated using a simultaneous equations method based on minimizing the following sum of squares:

$$
\min _{\sigma, p, \xi, b} \sum_{j=1}^{M}\left[C_{O B S}-\left(C_{B S}{ }_{j}(\sigma)+\rho \xi Q_{1}+\xi^{2} Q_{2}+\rho^{2} \xi^{2} Q_{3}\right)\right]^{2}
$$

Using this procedure, parameter estimates for $\sigma, \rho, \xi$, and $b$ are obtained. 


\section{TABLE II}

Comparison of Stochastic-Volatility-Adjusted Black-Scholes Prices and Observed Prices of S\&P 500 Index Options (SPX)

\begin{tabular}{|c|c|c|c|c|c|c|c|}
\hline $\begin{array}{l}\text { Trading } \\
\text { Date }\end{array}$ & $\begin{array}{c}\text { Number of } \\
\text { Price } \\
\text { Observations }\end{array}$ & $\begin{array}{l}\text { ISD } \\
(\%)\end{array}$ & $\begin{array}{c}\text { Implied } \\
\text { Correlation } \\
(p)\end{array}$ & $\begin{array}{c}\text { Implied } \\
\text { Volatility } \\
\text { of } \\
\text { Volatility } \\
\quad(\xi)\end{array}$ & $\begin{array}{l}\text { Half-Life } \\
\text { of } \\
\text { Volatility } \\
\text { (Days) }\end{array}$ & $\begin{array}{c}\text { Proportion of } \\
\text { Theoretical Prices } \\
\text { Outside Bid-Ask } \\
\text { Spread }\end{array}$ & $\begin{array}{c}\text { Average Deviation } \\
\text { of Theoretical } \\
\text { Prices from Spread } \\
\text { Boundaries }(\$)\end{array}$ \\
\hline 2/2/95 & 213 & 14.20 & -0.54 & 1.32 & 18.59 & 0.53 & 0.29 \\
\hline 2/6/95 & 239 & 13.65 & -0.49 & 1.15 & 21.81 & 0.59 & 0.50 \\
\hline 2/8/95 & 241 & 13.54 & -0.54 & 1.20 & 19.88 & 0.58 & 0.52 \\
\hline 2/10/95 & 242 & 13.20 & -0.51 & 1.10 & 20.18 & 0.52 & 0.44 \\
\hline 2/14/95 & 203 & 12.89 & -0.52 & 1.10 & 18.09 & 0.51 & 0.22 \\
\hline 2/16/95 & 203 & 13.95 & -0.53 & 1.27 & 18.19 & 0.67 & 0.34 \\
\hline 2/22/95 & 222 & 14.32 & -0.53 & 1.29 & 20.00 & 0.55 & 0.44 \\
\hline 2/24/95 & 227 & 13.89 & -0.50 & 1.42 & 15.14 & 0.44 & 0.28 \\
\hline 2/28/95 & 212 & 14.66 & -0.48 & 1.36 & 17.89 & 0.43 & 0.21 \\
\hline Average & 222 & 13.81 & -0.52 & 1.25 & 18.86 & 0.53 & 0.36 \\
\hline
\end{tabular}

Notes: On each day indicated, ISD, correlation, volatility of volatility, and mean reversion elasticity coefficient parameters are estimated from one-day lagged price observations. Theoretical option prices are then calculated using these implied parameters. All price observations correspond to call options traded in February 1995.

In turn, these parameter estimates are used to compute theoretical stochastic volatility option prices. Deviations of market-observed prices from theoretical prices are then calculated.

Table II summarizes empirical results obtained using the stochasticvolatility-adjusted option pricing model. Price data used here are identical to the data used to produce Table I. Thus, columns 1 and 2 of Table II are identical to those in Table I. However, to test the out-of-sample prediction power for the stochastic volatility model, parameter estimates listed in columns 3-6 are one-day lagged parameter estimates. Only these one-day lagged parameter estimates are used to calculate theoretical option prices. Therefore, the empirical results reported in Table II are based on out-of-sample parameter estimates.

For each day listed in Table II, columns 3-5 list parameter estimates for $\sigma, \rho$, and $\xi$. Column 6 reports values for the estimated half-life in days of a stochastic volatility deviation. These values are calculated as $-365(\ln 2) / b$. The column average return volatility $(\sigma)$ is $13.81 \%$ which is slightly higher than the corresponding average ISD reported in Table I. All implied correlation coefficients between stock returns and volatility changes are negative, with a column average correlation of -0.52 . Implied volatility of volatility $(\xi)$ values have a column average of 1.25 . Based on the estimated mean reversion coefficients $(b)$, the volatility half-life 
estimates have a column average value of 18.86 days. Overall, the empirical results reported in columns 4-6 strongly support the stochastic volatility model. These parameter estimates explain well the moneyness bias of the Black-Scholes model shown in Figure 1, since a negative correlation between stock returns and volatility changes leads the BlackScholes formula to underprice in-the-money call options and to overprice out-of-the-money call options.

Negative correlation between stock index returns and volatility has the following implications. On the one hand, when the stock index return is high, volatility tends to be low. On the other hand, when the stock index return is low, volatility tends to be high. This yields an asymmetric distribution of returns where a large negative return is significantly more likely to occur than a large positive return. This manifests itself in the form of a high implied volatility for in-the-money index calls and out-ofthe-money index puts, and a low implied volatility for out-of-the-money index calls and in-the-money index puts. By contrast, the Black-Scholes model assumes a constant volatility distribution in which large positive and negative returns have similar probabilities. Thus, compared to a stochastic volatility specification with a negative correlation between index returns and volatility, the Black-Scholes model overstates the likelihood of a large upward move in the S\&P 500 index and understates the likelihood of a large downward move.

Using the out-of-sample one-day lagged parameter estimates for $\sigma$, $\rho$, $\xi$, and $b$, one can evaluate the predictive power of the stochastic volatility option pricing model. Column 7 in Table II lists the proportion of theoretical prices predicted by the stochastic volatility model that lies outside observed bid-ask spreads. The column average proportion is 53\%, which represents a significant reduction from the corresponding average proportion of 95\% reported in Table I. For only those theoretical prices that lie outside observed spreads, column 8 reports average deviations from bid-ask spread boundaries. The column average deviation is $\$ 0.36$, which compares quite favorably with the average deviation of $\$ 0.59$ reported in Table I.

The statistical significance of the improvement in performance from out-of-sample stochastic volatility adjustments can be assessed using the following Z-statistic for the difference between two proportions (Hoel, 1984):

$$
Z=\frac{p_{1}-p_{2}}{\sqrt{p_{1}\left(1-p_{1}\right) / N_{1}+p_{2}\left(1-p_{2}\right) / N_{2}}}
$$

In this statistic, $p_{1}$ and $p_{2}$ are sample proportions, and $N_{1}$ and $N_{2}$ are 
sample sizes corresponding to these proportions. For example, Table I shows the volume-weighted average proportion, $p_{1}=0.947$, and Table II shows the volume-weighted average proportion, $p_{2}=0.536$. These proportions are almost identical to the simple averages reported in Tables I and II, and are based on a total sample size of $N=2002$ observations for all even-numbered days in the month. A quick computation yields a Z-statistic value of 33.66 , which is statistically significant at more than a 99.99\% level of confidence.

The statistical significance of improvements attributable to the stochastic volatility model can also be assessed using a simple sign test. The null hypothesis is that the stochastic volatility model does not systematically yield lower daily proportions of theoretical prices outside bid-ask spreads, in which case we can expect that half of the daily proportions reported in Table II are less than the corresponding daily proportions reported in Table I. The alternative hypothesis is that more than half of the stochastic volatility model daily proportions in Table II are less than the corresponding daily proportions in Table I. Comparing daily proportions in Tables I and II, all nine daily proportions listed in Table II are smaller than those listed in Table I. Under the null hypothesis, the probability of this occurring by chance is $1 / 2^{\circ}=1 / 512$. Thus, it is concluded that out-of-sample bias corrections for stochastic volatility provide a significant incremental performance improvement over the Black-Scholes model.

To visually assess the improvement attributable to a stochastic volatility bias correction, white squares in Figure 1 plot deviations of marketobserved call prices from theoretical stochastic volatility call prices. Figure 1 graphically reveals that almost all moneyness biases are eliminated by a stochastic volatility bias correction. This provides visual reinforcement for the numerical results presented in Tables I and II.

Procedures identical to those described above are applied to another sample of SPX options traded in April 1995. Tables III and IV and Figure 2 report results from this sample. Table III summarizes the performance of the Black-Scholes model. ISDs obtained from call options have a column average of $12.57 \%$ (column 3). Column 4 lists the proportion of theoretical Black-Scholes prices lying outside observed bid-ask spreads. The column average of $93 \%$ is almost identical to the average proportion of $95 \%$ reported in Table I. For those theoretical prices lying outside bidask spreads, the column average deviation is $\$ 1.29$, which is similar to the average deviation of $\$ 1.28$ reported in Table I. Black squares in Figure 2 graphically reinforce the conclusion that the Black-Scholes formula 
TABLE III

Comparison of Black-Scholes Prices and Observed Prices of S\&P 500 Index Options (SPX)

\begin{tabular}{lcccccc}
\hline Trading & $\begin{array}{c}\text { Number of } \\
\text { Price }\end{array}$ & $\begin{array}{c}\text { Proportion of } \\
\text { Theoretical Prices } \\
\text { Observations }\end{array}$ & $\begin{array}{c}\text { Average Deviation } \\
\text { Outside Bid-Ask } \\
\text { Spreads }\end{array}$ & $\begin{array}{c}\text { Theoretical Price } \\
\text { from Spread } \\
\text { Boundaries }(\$)\end{array}$ & $\begin{array}{c}\text { Average } \\
\text { Call Price }(\$)\end{array}$ & $\begin{array}{c}\text { Average } \\
\text { Bid-Ask Spread } \\
(\$)\end{array}$ \\
\hline $4 / 4 / 95$ & 265 & 12.86 & 0.95 & 1.39 & 25.05 & 0.70 \\
$4 / 6 / 95$ & 279 & 12.74 & 0.94 & 1.28 & 25.62 & 0.72 \\
$4 / 10 / 95$ & 270 & 12.91 & 0.93 & 1.29 & 25.49 & 0.76 \\
$4 / 12 / 95$ & 271 & 13.41 & 0.94 & 1.61 & 25.67 & 0.75 \\
$4 / 18 / 95$ & 209 & 12.40 & 0.91 & 1.07 & 26.40 & 0.76 \\
$4 / 20 / 95$ & 210 & 12.86 & 0.93 & 1.35 & 25.16 & 0.75 \\
$4 / 24 / 95$ & 258 & 12.71 & 0.94 & 1.53 & 24.81 & 0.73 \\
$4 / 26 / 95$ & 212 & 11.80 & 0.92 & 1.04 & 17.48 & 0.66 \\
$4 / 28 / 95$ & 222 & 11.46 & 0.93 & 1.04 & 23.74 & 0.66 \\
Average & 244 & 12.57 & 0.93 & 1.29 & 0.72 \\
\hline
\end{tabular}

Notes: On each day indicated, an ISD is estimated from one-day lagged price observations. Theoretical Black-Scholes option prices are then calculated using this ISD. All price observations correspond to call options traded in April 1995.

TABLE IV

Comparison of Stochastic-Volatility-Adjusted Black-Scholes Prices and Observed Prices of S\&P 500 Index Options (SPX)

\begin{tabular}{|c|c|c|c|c|c|c|c|}
\hline $\begin{array}{l}\text { Trading } \\
\text { Date }\end{array}$ & $\begin{array}{l}\text { Number of } \\
\text { Price } \\
\text { Observations }\end{array}$ & $\begin{array}{r}I S D \\
(\%)\end{array}$ & $\begin{array}{c}\text { Implied } \\
\text { Correlation } \\
(\rho)\end{array}$ & $\begin{array}{c}\text { Implied } \\
\text { Volatility } \\
\text { of } \\
\text { Volatility } \\
\quad(\xi)\end{array}$ & $\begin{array}{l}\text { Half-Life } \\
\text { of } \\
\text { Volatility } \\
\text { (Days) }\end{array}$ & $\begin{array}{c}\text { Proportion of } \\
\text { Theoretical Prices } \\
\text { Outside Bid-Ask } \\
\text { Spread }\end{array}$ & $\begin{array}{l}\text { Average Deviation } \\
\text { of Theoretical } \\
\text { Prices from Spread } \\
\text { Boundaries }(\$)\end{array}$ \\
\hline 4/4/95 & 265 & 15.19 & -0.47 & 1.17 & 25.47 & 0.53 & 0.41 \\
\hline 4/6/95 & 279 & 14.69 & -0.52 & 1.06 & 25.73 & 0.45 & 0.40 \\
\hline 4/10/95 & 270 & 14.60 & -0.56 & 0.96 & 29.26 & 0.45 & 0.41 \\
\hline 4/12/95 & 271 & 15.62 & -0.57 & 1.34 & 20.76 & 0.42 & 0.56 \\
\hline 4/18/95 & 209 & 13.52 & -0.55 & 0.89 & 26.33 & 0.30 & 0.22 \\
\hline 4/20/95 & 210 & 14.72 & -0.56 & 1.21 & 19.68 & 0.36 & 0.24 \\
\hline 4/24/95 & 258 & 14.67 & -0.60 & 1.39 & 16.83 & 0.33 & 0.36 \\
\hline $4 / 26 / 95$ & 212 & 13.10 & -0.56 & 0.87 & 28.28 & 0.22 & 0.11 \\
\hline 4/28/95 & 222 & 12.73 & -0.54 & 0.95 & 23.54 & 0.31 & 0.15 \\
\hline Average & 244 & 14.32 & -0.55 & 1.09 & 23.99 & 0.37 & 0.32 \\
\hline
\end{tabular}

Notes: On each day indicated ISD, correlation, volatility of volatility, and mean reversion elasticity coefficient parameters are estimated from one-day lagged price observations. Theoretical option prices are then calculated using these implied parameters. All price observations correspond to all options traded in April 1995. 


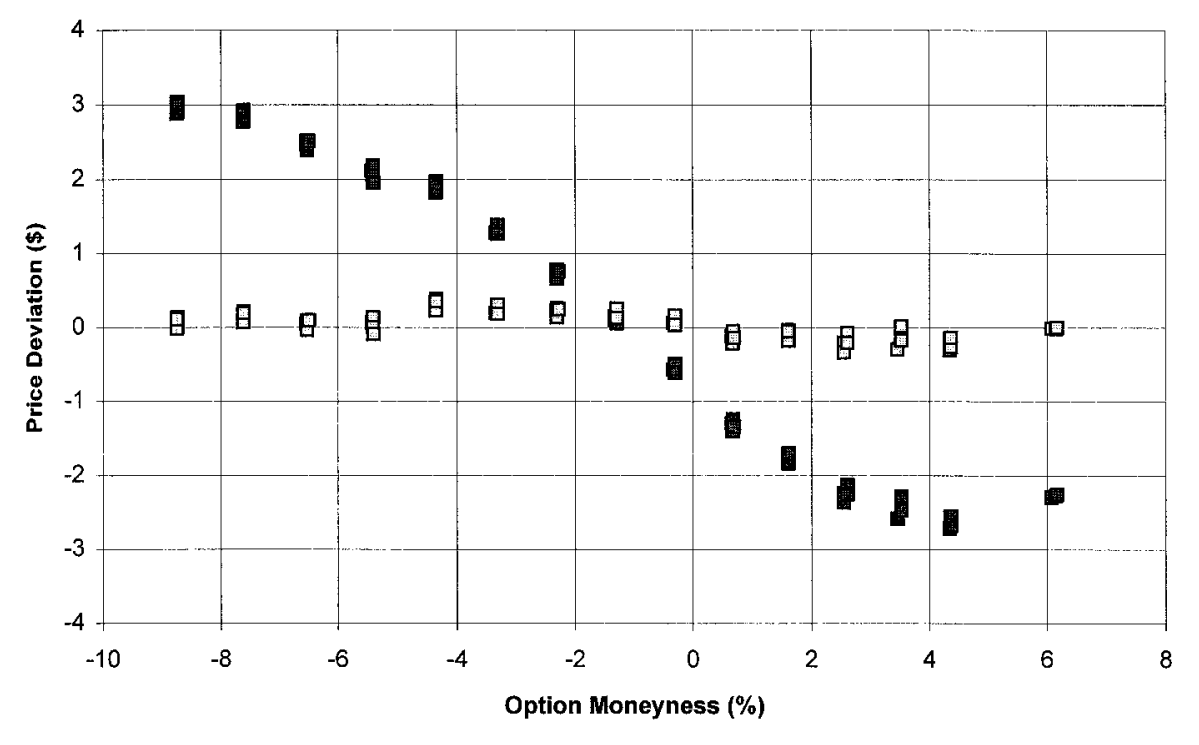

FIGURE 2

Mispricing of the Black-Scholes model and the Hull-White model (April 1995).

systematically misprices deep in-the-money and deep out-of-the-money options.

Table IV summarizes the performance of the stochastic volatility model. The original option prices used to produce this table are identical to those used to produce Table III; thus, columns 1 and 2 of both tables are identical. Columns 3-6 report stochastic volatility parameter estimates. The column average return volatility of $14.32 \%$ is slightly higher than that reported in Table III. Implied correlations have a column average value of -0.55 and implied volatility of volatility values have an overall average of 1.09. The column average stochastic volatility half-life is 23.99 days. Again, out-of-sample parameter estimates are used to calculate theoretical stochastic volatility model prices. Column 7 lists proportions of theoretical prices lying outside market-observed bid-ask spreads. The column average proportion is $37 \%$, which is significantly less than the average proportion of $93 \%$ reported in Table III. Column 8 lists average deviations from bid-ask spread boundaries. The column average deviation is $\$ 0.32$, which is substantially smaller than the $\$ 1.29$ average deviation reported in Table III. Finally, white squares in Figure 2 plot deviations of market-observed prices from theoretical prices. Figure 2 visually bolsters the conclusion that a stochastic volatility bias correction eliminates almost all moneyness bias from the Black-Scholes model.

In addition to results for the two months of 1995 data reported in this article, all procedures are applied to various data for option contracts 
traded in the years 1991 and 1994. Empirical results obtained from these data are essentially identical to results reported here.

\section{CONCLUSIONS}

This study uses the Hull and White (1988) stochastic volatility option pricing formula to study the stochastic process for the Standard \& Poor's 500 index implied by S\&P 500 index (SPX) options. It is found that a stochastic volatility option pricing formula provides a significant improvement over a constant volatility option pricing formula. This study contributes to the empirical options literature in at least two ways. First, it provides extensive evidence that observed option prices on the S\&P 500 index correspond to a mean-reverting stochastic volatility process, where return volatility is strongly negatively correlated with changes in stock index levels. Second, it shows that the parameters of a stochastic volatility process can be estimated from option prices and used to produce reliable predictions of day-ahead relationships between option prices and index levels. This represents a significant generalization of the common procedure of estimating an implied volatility from option prices.

\section{BIBLIOGRAPHY}

Bakshi, G., Cao, C., and Chen, Z. (1997): "Empirical Performance of Alternative Option Pricing Models," Journal of Finance, 52:2003-2049.

Barone-Adesi, G., and Whaley, R. E. (1986): "The Valuation of American Call Options and the Expected Ex-Dividend Stock Price Decline," Journal of Financial Economics, 17:91-111.

Bates, D. S. (1996): "Jumps and Stochastic Volatility: Exchange Rate Processes Implicit in Deutsche Mark Options," Review of Financial Studies, 9:69-107.

Beckers, S. (1980): "The Constant Elasticity of Variance Model and Its Implications for Option Pricing," Journal of Finance, 35:661-673.

Black, F. (1975): "Fact and Fantasy in the Use of Options," Financial Analysts Journal, 31:36-72.

Black, F., and Scholes, M. (1972): "The Valuation of Option Contracts and a Test of Market Efficiency,” Journal of Finance, 27:399-417.

Black, F., and Scholes, M. (1973): "The Pricing of Options and Corporate Liabilities," Journal of Political Economy, 81:637-659.

Bollerslev, T. (1986): "Generalized Autoregressive Conditional Heteroskedasticity," Journal of Econometrics, 31:307-327.

Bollerslev, T., Chou, R. Y., and Kroner, K. (1992): "ARCH Modeling in Finance: A Review of the Theory and Empirical Evidence," Journal of Econometrics, 52:5-59.

Christie, A. (1982): "The Stochastic Behavior of Common Stock Variances: Value, Leverage, and Interest Rate Effects," Journal of Financial Economics, 10:407-432. 
Cox, J. C., and Ross, S. A. (1976): "The Valuation of Options for Alternative Stochastic Processes," Journal of Financial Economics, 3:145-160.

Dothan, M. L. (1987): "A Random Volatility Correction for the Black-Scholes Option Pricing Formula," in Advances in Futures and Options Research, vol. 2. Greenwich, CT: JAI Press.

Engle, R. (1982): "Autoregressive Conditional Heteroskedasticity with Estimates of the Variance of United Kingdom Inflation," Econometrica, 50:987-1008.

Heston, S. L. (1993): "A Closed Form Solution for Options with Stochastic Volatility with Applications to Bond and Currency Options," Review of Financial Studies, 6:327-344.

Hillard, J. E., and Schwartz, A. (1996): "Binomial Option Pricing under Stochastic Volatility and Correlated State Variables," Journal of Derivatives, $3: 23-40$.

Hoel, P. G. (1984): Introduction to Mathematical Statistics. New York: John Wiley \& Sons.

Hull, J. C., and White, A. (1987): "The Pricing of Options on Assets with Stochastic Volatilities," Journal of Finance, 42:281-300.

Hull, J. C., and White, A. (1988): "An Analysis of the Bias in Option Pricing Caused by a Stochastic Volatility," in Advances in Futures and Options Research, vol. 3. Greenwich, CT: JAI Press.

Johnson, H., and Shanno, D. (1987): "Option Pricing When the Variance Is Changing," Journal of Financial and Quantitative Analysis, 22:143-151.

Merton, R. C. (1973): "The Theory of Rational Option Pricing," Bell Journal of Economics and Management Science, 4:141-183.

Merton, R. C. (1976a): "Option Pricing When Underlying Stock Returns Are Discontinuous," Journal of Financial Economics, 3:125-144.

Merton, R. C. (1976b): "The Impact on Option Pricing of Specification Error in the Underlying Stock Price Returns," Journal of Finance, 31:333-350.

Officer, R. R. (1973): "The Variability of the Market Factor of the NYSE," Journal of Business, 46:434-453.

Schmalensee, R., and Trippi, R. R. (1978): "Common Stock Volatility Expectations Implied by Option Premia," Journal of Finance, 33:129-147.

Scott, L. O. (1987): "Option Pricing When the Variance Changes Randomly: Theory, Estimation, and an Application,” Journal of Financial and Quantitative Analysis, 22:419-438.

Stein, E. M., and Stein, J. C. (1991): "Stock Price Distributions with Stochastic Volatility: An Analytic Approach,” Review of Financial Studies, 4:727-752.

Whaley, R. E. (1982): "Valuation of American Call Options on Dividend Paying Stocks," Journal of Financial Economics, 10:29-58.

Wiggins, J. B. (1987): "Option Values under Stochastic Volatility: Theory and Empirical Estimates,” Journal of Financial Economics, 19:351-372. 